Check for updates

Cite this: RSC Adv., 2019, 9, 17560

Received 25th April 2019 Accepted 27th May 2019

DOI: $10.1039 / c 9 r a 03082 d$

rsc.li/rsc-advances

\title{
Syntheses, structures, and magnetic properties of mixed-ligand complexes based on 3,6- bis(benzimidazol-1-yl)pyridazine $\uparrow$
}

\author{
Jun-Liang Dong, ${ }^{a}$ Peng-Yin Zhu, ${ }^{a}$ Jia-Qiang Du, ${ }^{a}$ Fei Xie, ${ }^{a}$ Hai-Ming Lan, ${ }^{a}$ \\ Ru-Xia Yang, ${ }^{a}$ Li-Zheng Yang ${ }^{a}$ and Duo-Zhi Wang (D) *ab
}

\begin{abstract}
Six new metal-organic coordination polymers (CPs) $\left[\mathrm{Ni}(\mathrm{L})(2,5-\mathrm{TDC})\left(\mathrm{H}_{2} \mathrm{O}\right)\right]_{n}(1),\left[\mathrm{Ni}(\mathrm{L})(1,3-\mathrm{BDC})\left(\mathrm{H}_{2} \mathrm{O}\right)\right]_{n}(2)$, $\left[\mathrm{Ni}(\mathrm{L})(1,4-\mathrm{BDC})\left(\mathrm{H}_{2} \mathrm{O}\right)\right]_{n}(3),\left[\mathrm{Mn}(\mathrm{L})(2,5-\mathrm{TDC})\left(\mathrm{H}_{2} \mathrm{O}\right)\right]_{n}(4),\left[\mathrm{Mn}(\mathrm{L})(2,6-\mathrm{PYDC})\left(\mathrm{H}_{2} \mathrm{O}\right)\right]_{n}(5)$ and $[\mathrm{Mn}(\mathrm{L})(1,4-\mathrm{NDC})]_{n}$ (6) were achieved by reactions of the corresponding metal salt with mixed organic ligands $(\mathrm{L}=3,6$ bis(benzimidazol-1-yl)pyridazine, 2,5- $\mathrm{H}_{2}$ TDC $=$ thiophene-2,5-dicarboxylic acid, 1,3- $\mathrm{H}_{2} \mathrm{BDC}=$ isophthalic acid, 1,4- $\mathrm{H}_{2} \mathrm{BDC}=$ terephthalic acid, 2,6- $\mathrm{H}_{2}$ PYDC = pyridine-2,6-dicarboxylic acid, 1,4$\mathrm{H}_{2} \mathrm{NDC}=$ naphthalene-1,4-dicarboxylic acid) under solvothermal condition. CPs 1-6 were characterized by single-crystal X-ray diffraction, IR, TG, XRD and elemental analyses. Their structures range from the intricate 3D CPs 1, 3, 4 and 6 to the 2D coordination polymer 2 and the infinite 1D chain 5 . The CPs 1-4 and 6 underlying networks were classified from the topological viewpoint, disclosing the distinct sql (in 1), pcu (in 3 and 6), new topology (in 2), and dia (in 4) topological nets. Moreover, analysis of thermal stability shows that they had good thermal stability. Finally, magnetic properties of CPs 1-6 have been studied, the results showed that complex 2 had ferromagnetic coupling and complexes 1, 3-6 were antiferromagnetic.
\end{abstract}

\section{Introduction}

Metal-organic coordination polymers (CPs), as a new class of inorganic-organic hybrid materials, have received extensive attention due to their structural diversity, interesting properties as well as potential application in some fields such as gas storage/separation, magnetism, catalysis and chemical sensing..$^{1-4}$ Particularly, the most important aspect is molecular magnets, in which the interesting magnetic properties such as SMMs (single molecule magnets) ${ }^{5}$ and SCMs (single chain magnets $)^{6}$ are closely related to the molecular topological structures. So this prompts researchers to study magnetostructural correlation for the purpose of deepening the understanding and improving the magnetic properties. However, the magnetic properties of the CPs can be fine-tuned by suitable modification of their chemical composition (varying the metal or metal cluster nodes and of the organic linkers). This in turn affects the coordination environments around the metal centers, and of the magnetic exchange pathways. ${ }^{7-10}$ The

${ }^{a}$ School of Chemistry and Chemical Engineering, Xinjiang University, Urumqi 830046, P. R. China. E-mail: xjwangdz@sina.com

${ }^{b}$ Key Laboratory of Energy Materials Chemistry, Ministry of Education, Urumqi, 830046 Xinjiang, P. R. China

$\dagger$ Electronic supplementary information (ESI) available. CCDC 1873981-1873986. For ESI and crystallographic data in CIF or other electronic format see DOI: $10.1039 / \mathrm{c} 9 \mathrm{ra03082d}$ inclusion of $\mathrm{N}$-donor ligands along with the ancillary carboxylate ligands is an interesting modification of the synthetic strategy. The coordination complementarity or competition between carboxylate and $\mathrm{N}$-donating ligands can significantly diversify the structure and magnetic features of the resulting CPs. ${ }^{11,12}$ Interestingly, experimental results have shown that the same building precursors may lead to completely different structural arrangements. ${ }^{13}$ It is proposed that the different structures might be caused by the subtle competitive relationship among various different coordination bonds. ${ }^{14}$ In this work, we have used benzimidazole ligands and different organic carboxylic acids to obtain six new complexes under the solvothermal condition with the $\mathrm{Ni}(\mathrm{II}) / \mathrm{Mn}$ (II) metal salt. Namely, $\left[\mathrm{Ni}(\mathbf{L})(2,5-\mathrm{TDC})\left(\mathrm{H}_{2} \mathrm{O}\right)\right]_{n} \quad$ (1), $\quad\left[\mathrm{Ni}(\mathbf{L})(1,3-\mathrm{BDC})\left(\mathrm{H}_{2} \mathrm{O}\right)\right]_{n} \quad$ (2), $\left[\mathrm{Ni}(\mathrm{L})(1,4-\mathrm{BDC})\left(\mathrm{H}_{2} \mathrm{O}\right)\right]_{n} \quad$ (3), $\quad\left[\mathrm{Mn}(\mathbf{L})(2,5-\mathrm{TDC})\left(\mathrm{H}_{2} \mathrm{O}\right)\right]_{n} \quad$ (4), $\left[\mathrm{Mn}(\mathbf{L})(2,6-\mathrm{PYDC})\left(\mathrm{H}_{2} \mathrm{O}\right)\right]_{n}$ (5) and $[\mathrm{Mn}(\mathbf{L})(1,4-\mathrm{NDC})]_{n}$ (6). The analysis of structure displays that their molecular structures are also diverse, including different kinds of 1-D chains, 2-D networks, and 3-D frameworks. In addition, the magnetic properties of complexes 1-6 have been investigated and discussed.

\section{Experimental}

\section{Materials and physical measurements}

Starting materials were analytical grade and used as commercially obtained without further purification (Scheme 1). The 


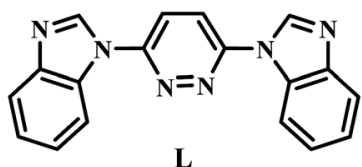

$\mathbf{L}$

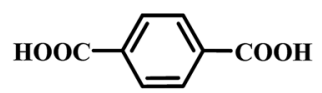

$1,4-\mathrm{H}_{2} \mathrm{BDC}$<smiles>O=C(O)c1ccc(C(=O)O)s1</smiles>

$2,5-\mathrm{H}_{2} \mathrm{TDC}$<smiles>O=C(O)c1cccc(C(=O)O)n1</smiles>

2,6- $\mathrm{H}_{2} \mathrm{PYDC}$

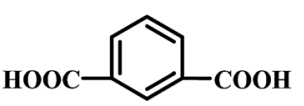

1,3- $\mathrm{H}_{2} \mathrm{BDC}$

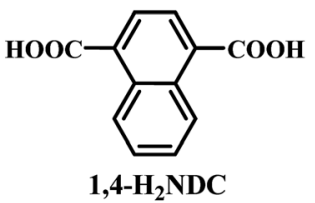

Scheme 1 The L ligand and organic acids used in this work.

ligand of $\mathbf{L}$ (Scheme 1) was synthesized by an analogous method described in the literature. ${ }^{15,16}$ Elemental analyses (C, H, and N) were performed by PerkinElmer 240 analyzer. FT-IR spectra were recorded by a Thermo Scientific Nicolet 6000 FT-IR spectrophotometer with $\mathrm{KBr}$ pellets in the $400-4000 \mathrm{~cm}^{-1}$ region. Powder X-ray diffraction (PXRD) data were recorded on a Rigaku D/Max-2500 diffractometer. Network topologies for all crystal structures were analyzed by using TOPOS4.0 software package. ${ }^{17}$ Thermogravimetric analyses were carried out by the Japan's neo-confucianism standard TG-DTA analyzer under a flow of Ar at a heating rate of $10{ }^{\circ} \mathrm{C} \mathrm{min}{ }^{-1}$. Magnetic measurements of the samples were performed on a SQUID MPMS-XL-7 magnetometer.

Synthesis of $\left[\mathrm{Ni}(\mathrm{L})(2,5-\mathrm{TDC})\left(\mathrm{H}_{2} \mathrm{O}\right)\right]_{n}$ (1). A mixture of $\mathrm{Ni}(\mathrm{AcO})_{2} \cdot 4 \mathrm{H}_{2} \mathrm{O}(24.8 \mathrm{mg}, 0.1 \mathrm{mmol}), 2,5-\mathrm{H}_{2} \mathrm{TDC}(17.2 \mathrm{mg}, 0.1$ $\mathrm{mmol})$, and $\mathbf{L}(31.2 \mathrm{mg}, 0.1 \mathrm{mmol})$ in $8 \mathrm{~mL}$ of solution $\left(\mathrm{V}_{\mathrm{H}_{2} \mathrm{O}^{-}}\right.$ $\left.: \mathrm{V}_{\mathrm{CH}_{3} \mathrm{CN}}=2: 1\right)$ was sealed in a teflon-lined autoclave $(25 \mathrm{~mL})$ and heated at $160{ }^{\circ} \mathrm{C}$ for $12 \mathrm{~h}$, and then cooled down to room temperature. Green stripe crystals of $\mathbf{1}$ were collected and washed with water. Yield: $\sim 42 \%$ based on $\mathrm{L}$ ligand. Elemental analysis (\%): anal. calcd for $\mathrm{C}_{24} \mathrm{H}_{16} \mathrm{~N}_{6} \mathrm{O}_{5} \mathrm{SNi}$ : C, $51.54 ; \mathrm{H}, 2.88 ; \mathrm{N}$, 15.03. Found: C, 51.45; H, 2.73; N, 15.12. IR ( $\mathrm{cm}^{-1}$, KBr pellets): $3354 \mathrm{w}, 3132 \mathrm{w}, 3104 \mathrm{w}, 3080 \mathrm{w}, 2903 \mathrm{w}, 1607 \mathrm{w}, 1565 \mathrm{~m}, 1527 \mathrm{~s}$, $1478 \mathrm{~m}, 1458$ s, 1438 s, 1399 s, 1372 s, 1304 m, 1150 m, 1032 m, $773 \mathrm{~s}, 738 \mathrm{~s}, 686 \mathrm{~m}, 626 \mathrm{~m}$.

Synthesis of $\left[\mathrm{Ni}(\mathrm{L})(1,3-\mathrm{BDC})\left(\mathrm{H}_{2} \mathrm{O}\right)\right]_{n}$ (2). A mixture of $\mathrm{Ni}\left(\mathrm{NO}_{3}\right)_{2} \cdot 6 \mathrm{H}_{2} \mathrm{O}(29.0 \mathrm{mg}, 0.1 \mathrm{mmol}), 1,3-\mathrm{H}_{2} \mathrm{BDC}(16.6 \mathrm{mg}, 0.1$ $\mathrm{mmol})$, and $\mathbf{L}(31.2 \mathrm{mg}, 0.1 \mathrm{mmol})$ in $8 \mathrm{~mL}$ of solution $\left(\mathrm{V}_{\mathrm{H}_{2} \mathrm{O}^{-}}\right.$ $\left.: \mathrm{V}_{\mathrm{DMF}}=1: 1\right)$ was sealed in a teflon-lined autoclave $(25 \mathrm{~mL})$ and heated at $140{ }^{\circ} \mathrm{C}$ for $12 \mathrm{~h}$, and then cooled down to room temperature. Green stripe crystals of 2 were collected and washed with water. Yield: $\sim 46 \%$ based on $\mathbf{L}$ ligand. Elemental analysis (\%): anal. calcd for $\mathrm{C}_{26} \mathrm{H}_{17} \mathrm{~N}_{6} \mathrm{O}_{5} \mathrm{Ni}: \mathrm{C}, 56.45 ; \mathrm{H}, 3.23 ; \mathrm{N}$, 15.13. Found: C, 56.56; H, 3.10; N, 15.22. IR ( $\mathrm{cm}^{-1}, \mathrm{KBr}$ pellets): 3439 w, 3123 w, 3087 w, 3029 w, 1611 m, 1564 m, 1529 s, 1460 s, $1441 \mathrm{~s}, 1404 \mathrm{~m}, 1381 \mathrm{~s}, 1314 \mathrm{~m}, 1248 \mathrm{~m}, 1149 \mathrm{~m}, 1030 \mathrm{~m}, 744 \mathrm{~s}$, $720 \mathrm{~s}, 620 \mathrm{~m}$.

Synthesis of $\left[\mathrm{Ni}(\mathrm{L})(1,4-\mathrm{BDC})\left(\mathrm{H}_{2} \mathrm{O}\right)\right]_{n}$ (3). A mixture of $\mathrm{Ni}(\mathrm{AcO})_{2} \cdot 4 \mathrm{H}_{2} \mathrm{O}(24.8 \mathrm{mg}, 0.1 \mathrm{mmol}), 1,4-\mathrm{H}_{2} \mathrm{BDC}(16.6 \mathrm{mg}, 0.1$ $\mathrm{mmol})$, and $\mathbf{L}(31.2 \mathrm{mg}, 0.1 \mathrm{mmol})$ in $6 \mathrm{~mL}$ of solution $\left(\mathrm{V}_{\mathrm{H}_{2} \mathrm{O}^{-}}\right.$ $\left.: \mathrm{V}_{\mathrm{CH}_{3} \mathrm{OH}}=1: 1\right)$ was sealed in a teflon-lined autoclave $(25 \mathrm{~mL})$ and heated at $130{ }^{\circ} \mathrm{C}$ for $12 \mathrm{~h}$, and then cooled down to room temperature. Green stripe crystals of 3 were collected and washed with water. Yield: $\sim 35 \%$ based on $\mathbf{L}$ ligand. Elemental analysis (\%): anal. calcd for $\mathrm{C}_{26} \mathrm{H}_{18} \mathrm{~N}_{6} \mathrm{O}_{5} \mathrm{Ni}$ : C, $56.45 ; \mathrm{H}, 3.28 ; \mathrm{N}$, 15.19. Found: C, 56.56; H, 3.10; N, 15.22. IR ( $\mathrm{cm}^{-1}$, $\mathrm{KBr}$ pellets): $3271 \mathrm{~m}, 3139 \mathrm{w}, 3076 \mathrm{w}, 2824 \mathrm{w}, 1605 \mathrm{~m}, 1567 \mathrm{~s}, 1520 \mathrm{~s}, 1506 \mathrm{~s}$, $1478 \mathrm{~m}, 1456 \mathrm{~s}, 1440 \mathrm{~s}, 1392 \mathrm{~s}, 1362 \mathrm{~m}, 1300 \mathrm{~m}, 1248 \mathrm{~m}, 1187 \mathrm{w}$, $1149 \mathrm{~m}, 1034 \mathrm{~m}, 760 \mathrm{~m}, 747 \mathrm{~s}$.

Synthesis of $\left[\mathrm{Mn}(\mathrm{L})(2,5-\mathrm{TDC})\left(\mathrm{H}_{2} \mathrm{O}\right)\right]_{n}$ (4). Preparation of complex 4 was similar to that of $\mathbf{1}$, except that $\mathrm{Mn}(\mathrm{AcO})_{2} \cdot 4 \mathrm{H}_{2} \mathrm{O}$ $(24.5 \mathrm{mg}, 0.1 \mathrm{mmol})$ was used instead of $\mathrm{Ni}(\mathrm{AcO})_{2} \cdot 4 \mathrm{H}_{2} \mathrm{O}$. Orange prisms crystals of 4 were collected and washed with methanol. Yield: $\sim 38 \%$ based on $\mathbf{L}$ ligand. Elemental analysis (\%): anal. calcd for $\mathrm{C}_{24} \mathrm{H}_{16} \mathrm{~N}_{6} \mathrm{O}_{5} \mathrm{SMn}$ : C 51.89, $\mathrm{H} 2.90, \mathrm{~N} 15.13$. Found (\%): C 51.76, H 2.75, N 15.02. IR ( $\mathrm{cm}^{-1}$, KBr pellets): 3376 m, 3117 m, 1963 w, 1686 w, 1566 s, 1525 s, 1457 s, 1375 s, 1209 s, $1031 \mathrm{~m}, 997 \mathrm{~m}, 824 \mathrm{~m}, 764 \mathrm{~m}, 747 \mathrm{~m}$.

Synthesis of $\left[\mathrm{Mn}(\mathrm{L})(2,6-\mathrm{PYDC})\left(\mathrm{H}_{2} \mathrm{O}\right)\right]_{n}$ (5). A mixture of $\mathrm{Mn}\left(\mathrm{BF}_{4}\right)_{2} \cdot \mathrm{H}_{2} \mathrm{O}(15.9 \mathrm{mg}, 0.1 \mathrm{mmol}), 2,6-\mathrm{H}_{2} \mathrm{PYDC}(16.7 \mathrm{mg}, 0.1$ $\mathrm{mmol}), \mathrm{NaOH}(8 \mathrm{mg}, 0.20 \mathrm{mmol})$ and $\mathbf{L}(31.2 \mathrm{mg}, 0.1 \mathrm{mmol})$ in $8 \mathrm{~mL}$ of water was sealed in a teflon-lined autoclave $(25 \mathrm{~mL})$ and heated at $160{ }^{\circ} \mathrm{C}$ for $12 \mathrm{~h}$, and then cooled down to room temperature. Orange stripe crystals of $\mathbf{5}$ was collected and washed with methanol. Yield: $\sim 40 \%$ based on $\mathbf{L}$ ligand. Elemental analysis (\%): anal. calcd for $\mathrm{C}_{25} \mathrm{H}_{17} \mathrm{~N}_{7} \mathrm{O}_{5} \mathrm{Mn}$ : C, 54.56; H, 3.11; N, 17.81. Found: C, 54.47; H, 3.03; N, 17.70. IR $\left(\mathrm{cm}^{-1}\right.$, KBr pellets): $3334 \mathrm{~m}, 3150 \mathrm{~m}, 3082 \mathrm{~m}, 2963 \mathrm{~m}, 2003 \mathrm{w}, 1609 \mathrm{~s}$, 1456 s, 1435 s, 1392 s, 1363 s, 1209 s, 724 s, 749 s.

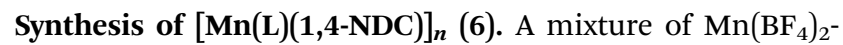
$\cdot \mathrm{H}_{2} \mathrm{O}(15.9 \mathrm{mg}, 0.1 \mathrm{mmol}), 1,4-\mathrm{H}_{2} \mathrm{NDC}(21.6 \mathrm{mg}, 0.1 \mathrm{mmol})$, $\mathrm{NaOH}(40 \mathrm{mg}, 1 \mathrm{mmol})$ and $\mathbf{L}(31.2 \mathrm{mg}, 0.1 \mathrm{mmol})$ in $8 \mathrm{~mL}$ of water was sealed in a teflon-lined autoclave $(25 \mathrm{~mL})$ and heated at $140{ }^{\circ} \mathrm{C}$ for $12 \mathrm{~h}$, and then cooled down to room temperature. Orange stripe crystals of 6 were collected and washed with methanol. Yield: $\sim 42 \%$ based on $\mathrm{L}$ ligand. Elemental analysis (\%): anal. calcd for $\mathrm{C}_{30} \mathrm{H}_{18} \mathrm{~N}_{6} \mathrm{O}_{4} \mathrm{Mn}: \mathrm{C}, 61.97 ; \mathrm{H}, 3.12$; N, 14.45. Found: C, 61.85; H, 3.03; N, 14.28. IR ( $\mathrm{cm}^{-1}$, KBr pellets): 3642 w, 3149 w, 3060 w, 1945 w, 1589 m, 1552 s, 1505 s, 1458 s, 1435 s, $1361 \mathrm{~s}, 1241 \mathrm{~m}, 1203 \mathrm{~m}, 829 \mathrm{~m}, 783 \mathrm{~m}, 740 \mathrm{~m}$.

\section{X-ray crystallography}

The crystallographic data of complexes 1-6 were collected on a Bruker SMART Apex II diffractometer equipped with graphitemonochromatic Mo K $\alpha$ radiation $(\lambda=0.71073 \AA)$ at $298 \mathrm{~K}$ using a multi-scan technique. All the structures were solved by the direct method of SHELXS-2014 and refined by full-matrix least- 
squares on $F^{2}$ with anisotropic displacement using SHELXTL software package. ${ }^{18}$ The disordered segments were subjected to geometric restraints during the refinements. Non-hydrogen atoms were refined with anisotropic displacement parameters during the final cycles. All hydrogen atoms were located in calculated positions and refined isotropically, except the hydrogen atoms of water molecules were fixed in a difference Fourier map and refined isotropically. Crystallographic data and structure refinement details for structural analyses are summarized in Table 1 and the selected bond lengths and angles are given in Table S1 of ESI. $\dagger$

CCDC 1873981-1873986 contains the supplementary crystallographic data for complexes $\left[\mathrm{Ni}(\mathrm{L})(2,5-\mathrm{TDC})\left(\mathrm{H}_{2} \mathrm{O}\right)\right]_{n} \quad$ (1), $\left[\mathrm{Ni}(\mathbf{L})(1,3-\mathrm{BDC})\left(\mathrm{H}_{2} \mathrm{O}\right)\right]_{n} \quad(2), \quad\left[\mathrm{Ni}(\mathbf{L})(1,4-\mathrm{BDC})\left(\mathrm{H}_{2} \mathrm{O}\right)\right]_{n} \quad(3)$, $\left[\mathrm{Mn}(\mathbf{L})(2,5-\mathrm{TDC})\left(\mathrm{H}_{2} \mathrm{O}\right)\right]_{n}(\mathbf{4}),\left[\mathrm{Mn}(\mathbf{L})(2,6-\mathrm{PYDC})\left(\mathrm{H}_{2} \mathrm{O}\right)\right]_{n}$ (5) and $[\mathrm{Mn}(\mathbf{L})(1,4-\mathrm{NDC})]_{n}(\mathbf{6})$, respectively.

\section{Results and discussion}

\section{Description of the crystal structure}

Structure of $\left[\mathrm{Ni}(\mathrm{L})(2,5-\mathrm{TDC})\left(\mathrm{H}_{2} \mathrm{O}\right)\right]_{n}$ (1). Single-crystal X-ray diffraction analysis reveals that complex $\mathbf{1}$ is based on a dense 3 -fold interpenetrating three-dimensional (3D) framework and crystallizes in the monoclinic space group $C c$. The construction unit of the 3D framework consists of one $\mathrm{Ni}$ ion, one $\mathbf{L}$ ligand, one 2,5-TDC ${ }^{2-}$ anion and one water molecule of coordination. The Ni1 ion is six-coordinated and the coordination geometry around the individual $\mathrm{Ni}$ center is a distorted octahedron which the equatorial plane are occupied by $\mathrm{O} 1, \mathrm{O} 2, \mathrm{O}^{\# 1}$ and $\mathrm{O}^{\# 1}$ donor atoms, and the axial sites are occupied by $\mathrm{N} 1$ and $\mathrm{N6}^{\# 2}$ atoms with an N1-Ni1-N6 ${ }^{\# 2}$ angle of $171.74^{\circ}$. The $\mathrm{O} 1, \mathrm{O} 2, \mathrm{O}^{\# 1}$ and $\mathrm{O5}^{\# 1}$ donor atoms come from two different 2,5-TDC ${ }^{2-}$ ligands and one water molecule of coordination, and the N1 and $\mathrm{N}^{\# 2}$ sites originate from the bis-bidentate bridging ligand (Fig. 1a). The lengths of Ni-N bond are 2.077(5) and 2.080(5) $\AA$, while the lengths of $\mathrm{Ni}-\mathrm{O}$ bond is in the range of 2.038(4)2.264(4) ̊..

Adjacent Ni centers were connected by carboxylate ligands to form a $1 \mathrm{D}$ chain with the $\mathrm{Ni} \cdots \mathrm{Ni}$ distance of $10.4767 \AA$, then adjacent $1 \mathrm{D}$ chains are further extended by other $\mathbf{L}$ ligands to give the 2D plane network structure (Fig. 1b). The 2,5-TDC ${ }^{2-}$ ligand adopts $\left(\kappa^{2}\right)-\left(\kappa^{1}\right)-\mu_{2}$ coordination mode (Scheme $2 \mathrm{~A}$ ) and the $\mathbf{L}$ ligand adopts bidentate bridging coordination. The $2 \mathrm{D}$ layers are further extended by residual carboxylate groups and $\mathbf{L}$ ligands to give the 3D Ni-organic framework (Fig. 1c), the $\mathrm{Ni}$ center is connected by organic ligands to four neighboring $\mathrm{Ni}$ centers. Thus, the Ni centers can be considered as a 4-connected node and the ligands can be considered as linkers. Topological analysis reveals that $\mathbf{1}$ is a uninodal 4-connected network with the point symbol of $\left\{6^{6}\right\}$-sql topology (Fig. 1d).

Structure of $\left[\mathrm{Ni}(\mathrm{L})(\mathbf{1}, 3-\mathrm{BDC})\left(\mathrm{H}_{2} \mathrm{O}\right)\right]_{n}$ (2). Complex 2 crystallizes in the monoclinic $C 2 / c$ space group in which one $\mathrm{Ni}$ ion, one $\mathbf{L}$ ligand, one $1,3-\mathrm{BDC}^{2-}$ anion and one molecule of coordination water constitute the construction unit. The Ni1 ion is six-coordinated that ligated by four $\mathrm{O}$ atoms $(\mathrm{O} 1, \mathrm{O} 2, \mathrm{O} 4$ and O5) originating from two different $1,3-\mathrm{BDC}^{2-}$ ligands and one water molecule of coordination in the equatorial plane position and two $\mathrm{N}$ atoms ( $\mathrm{N} 1$ and $\mathrm{N} 6$ ) form two different $\mathbf{L}$ ligands at axial positions (Fig. 2a) with an N1-Ni1-N6 angle of $176.92^{\circ}$. Analysis of the coordination geometry around the Ni center showed that the ion resides in a distorted octahedral environment. The lengths of $\mathrm{Ni}-\mathrm{N}$ bond are 2.0879(15) and 2.1053(15)

Table 1 Crystal data and structure refinement summary for complexes 1-6

\begin{tabular}{|c|c|c|c|c|c|c|}
\hline & 1 & 2 & 3 & 4 & 5 & 6 \\
\hline Formula & $\mathrm{C}_{24} \mathrm{H}_{16} \mathrm{~N}_{6} \mathrm{O}_{5} \mathrm{SNi}$ & $\mathrm{C}_{26} \mathrm{H}_{17} \mathrm{~N}_{6} \mathrm{O}_{5} \mathrm{Ni}$ & $\mathrm{C}_{26} \mathrm{H}_{18} \mathrm{~N}_{6} \mathrm{O}_{5} \mathrm{Ni}$ & $\mathrm{C}_{24} \mathrm{H}_{16} \mathrm{~N}_{6} \mathrm{O}_{5} \mathrm{SMn}$ & $\mathrm{C}_{25} \mathrm{H}_{17} \mathrm{~N}_{7} \mathrm{O}_{5} \mathrm{Mn}$ & $\mathrm{C}_{30} \mathrm{H}_{18} \mathrm{~N}_{6} \mathrm{O}_{4} \mathrm{Mn}$ \\
\hline Formula wt & 559.2 & 552.16 & 553.17 & 555.43 & 550.4 & 581.44 \\
\hline Crystal system & Monoclinic & Monoclinic & Monoclinic & Monoclinic & Triclinic & Monoclinic \\
\hline Space group & $C c$ & $C 2 / c$ & $P n$ & $C c$ & $P-1$ & $P 2_{1} / n$ \\
\hline$T(\mathrm{~K})$ & 170.15 & 100.00 & 100.00 & 173.15 & 100.00 & 173.15 \\
\hline$a(\AA)$ & $13.039(5)$ & $16.6905(7)$ & $11.7121(4)$ & $19.829(3)$ & $9.3365(7)$ & $11.035(3)$ \\
\hline$b(\AA)$ & $18.606(7)$ & $11.6251(3)$ & $6.1520(2)$ & $5.8486(10)$ & $11.9034(11)$ & $9.024(2)$ \\
\hline$c(\AA)$ & $10.943(6)$ & $26.5469(13)$ & $16.1276(4)$ & $20.750(3)$ & $11.9507(11)$ & $24.497(6)$ \\
\hline$\alpha\left({ }^{\circ}\right)$ & 90 & 90 & 90 & 90 & $66.724(9)$ & 90 \\
\hline$\beta\left(^{\circ}\right)$ & $121.201(6)$ & $110.743(5)$ & $91.235(3)$ & $109.388(4)$ & 68.005 & $97.215(6)$ \\
\hline$\gamma\left({ }^{\circ}\right)$ & 90 & 90 & 90 & 90 & 77.863 & 90 \\
\hline$V\left(\AA^{3}\right)$ & $2270.8(17)$ & $4817.0(4)$ & $1161.77(6)$ & $2270.0(6)$ & $1128.2(2)$ & $2420.2(10)$ \\
\hline$Z$ & 4 & 8 & 2 & 4 & 2 & 4 \\
\hline$D\left(\mathrm{mg} \mathrm{m}^{-3}\right)$ & 1.636 & 1.523 & 1.581 & 1.625 & 1.62 & 1.596 \\
\hline$\mu\left(\mathrm{mm}^{-1}\right)$ & 0.998 & 0.857 & 0.888 & 0.726 & 0.641 & 0.599 \\
\hline$F(000)$ & 1144 & 2264 & 568 & 1132 & 562 & 1188 \\
\hline Crystal size $\left(\mathrm{mm}^{3}\right)$ & $0.23 \times 0.19 \times 0.15$ & $0.15 \times 0.13 \times 0.11$ & $0.13 \times 0.12 \times 0.11$ & $0.25 \times 0.18 \times 0.11$ & $0.18 \times 0.15 \times 0.12$ & $0.23 \times 0.19 \times 0.17$ \\
\hline Theta rang (deg) & $2.129-26.698$ & $3.282-29.555$ & $2.127-29.619$ & $1.040-27.583$ & $3.525-29.506$ & $1.676-27.473$ \\
\hline $\operatorname{Goof}\left(F^{2}\right)$ & 1.059 & 1.077 & 1.028 & 1.049 & 1.042 & 1.007 \\
\hline Measured refins & 7171 & 22593 & 14734 & 16528 & 10282 & 21200 \\
\hline Obsd refins & 3970 & 5961 & 5313 & 4747 & 5286 & 5518 \\
\hline$R_{\text {int }}$ & 0.0331 & 0.0303 & 0.0424 & 0.0426 & 0.0278 & 0.0941 \\
\hline$R^{a} / \mathrm{w} R^{b}$ & $0.0353 / 0.0999$ & $0.0363 / 0.0820$ & $0.0361 / 0.0687$ & $0.0320 / 0.0775$ & $0.0403 / 0.0982$ & $0.0502 / 0.1143$ \\
\hline
\end{tabular}

${ }^{a} R=\Sigma\left(|| F_{0}|-| F_{\mathrm{C}} \|\right) / \Sigma\left|F_{0}\right| \cdot{ }^{b} \mathrm{w} R=\left[\Sigma \mathrm{w}\left(\left|F_{0}\right|^{2}-\left|F_{\mathrm{C}}\right|^{2}\right)^{2} / \Sigma \mathrm{w}\left(F_{0}{ }^{2}\right)\right]^{1 / 2}$. 


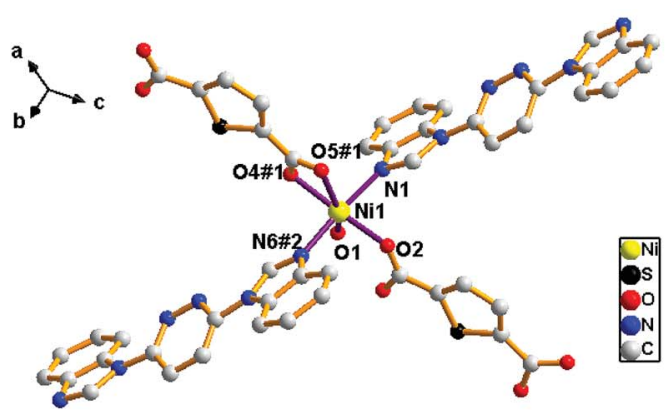

(a)

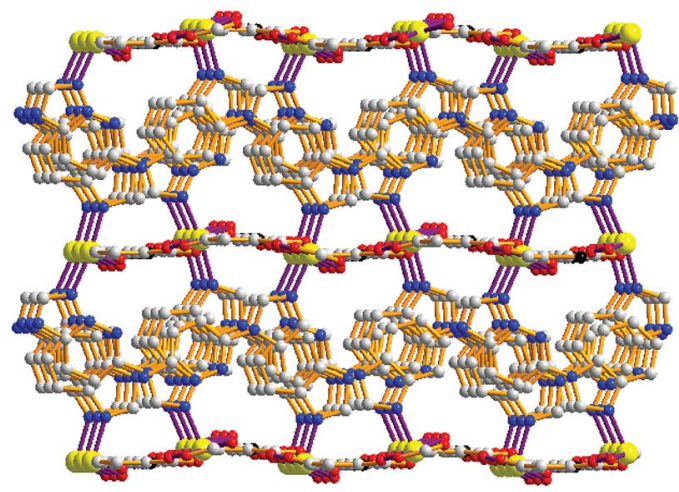

(c)

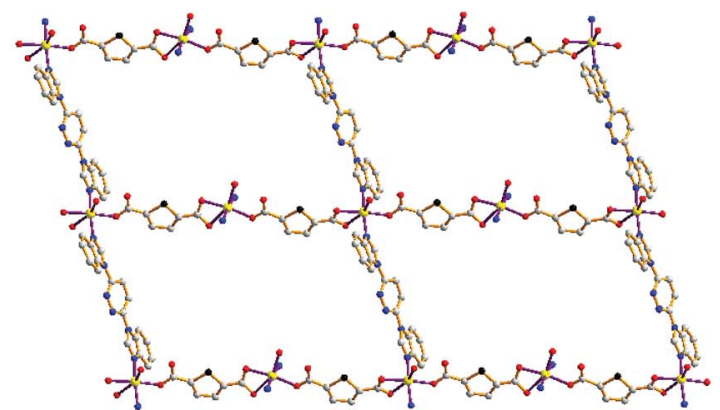

(b)

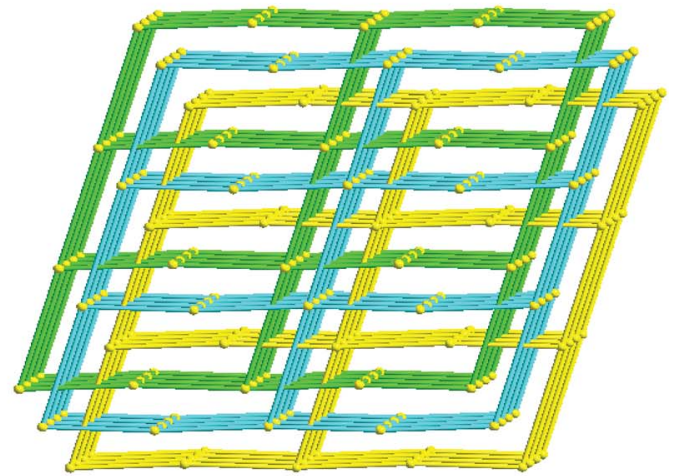

(d)

Fig. 1 View of (a) the coordination environment of $\mathrm{Ni}\left({ }^{\prime}\right)$ atom in complex 1; (b) the 2D plane structure of 1; (c) the 3D framework structure of 1; (d) the 4-connected net topology with the Schläfli symbol of $\left(6^{6}\right)$.

$\AA$, while the lengths of $\mathrm{Ni}-\mathrm{O}$ bond is in the range of 1.9934(12)2.1362(12) ^.

The outstanding structural feature of complex 2 is the presence of two types helical chains (Fig. 2b), the Ni1 ion is bridged by two $\mathrm{N}$ atoms from $\mathbf{L}$ ligands to form an infinitely extended double helical chain of left-handed and right-handed along the $b$-axis. These helical chains are then connected via other 1,3$\mathrm{BDC}^{2-}$ ligands in a $\left(\kappa^{2}\right)-\left(\kappa^{1}\right)-\mu_{2}$ coordination mode (Scheme $\left.2 \mathrm{~B}\right)$ to generate an infinitely extended 2D network structure. Furthermore, structural analysis showed that 2D Ni-organic network of two-fold interpenetration structure (Fig. 2c). For a better understanding of the intricate framework, a topological analysis of complex 2 was performed. In the 2D network structure, we can define the $\mathrm{Ni}$ ion as four-connected nodes with all crystallographically independent $\mathbf{L}$ ligands and $1,3-\mathrm{BDC}^{2-}$ anion as linkers. Therefore, the two-fold interpenetration structure of 2 can be represented as a 6-connected new topology with the point symbol of $\left(4^{12} \cdot 6^{3}\right)$ (Fig. 2d).

Structure of $\left[\mathrm{Ni}(\mathrm{L})(\mathbf{1}, \mathbf{4 - \mathrm { BDC }})\left(\mathrm{H}_{2} \mathrm{O}\right)\right]_{n}$ (3). When $1,4-\mathrm{H}_{2} \mathrm{BDC}$ was introduced in place of $1,3-\mathrm{H}_{2} \mathrm{BDC}$, complex 3 was obtained. Single-crystal X-ray diffraction analysis reveals that complex 3 is based on a dense 3D framework and crystallizes in the monoclinic space group $P n$. The construction unit of the 3D framework consists of one $\mathrm{Ni}$ ion, one $\mathbf{L}$ ligand, one $1,4-\mathrm{BDC}^{2-}$ anion<smiles></smiles>

A<smiles></smiles>

B<smiles></smiles>

C<smiles></smiles>

D<smiles>[M]OC(=O)c1ccc(C(=O)O[Al])c2ccccc12</smiles>

E

Scheme 2 The coordination mode of organic acids in this work. 


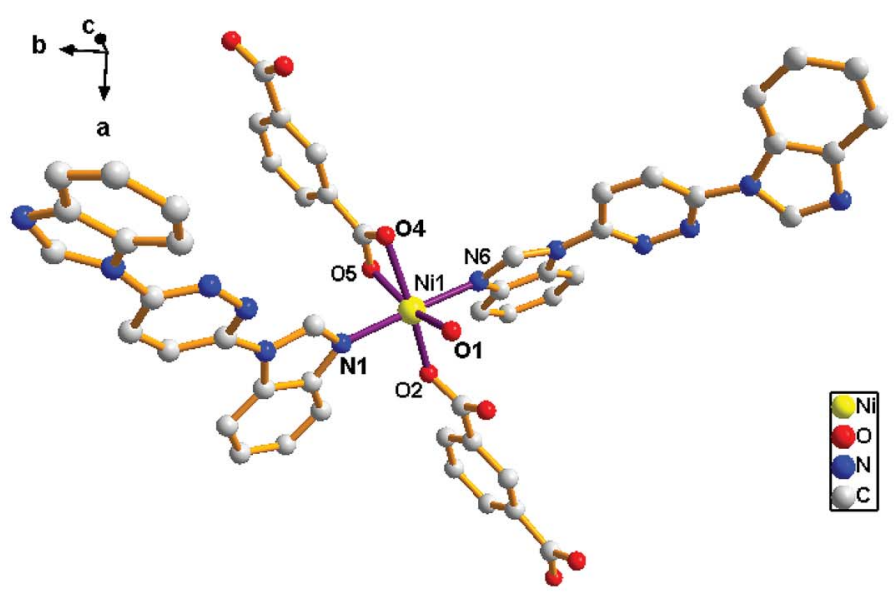

(a)

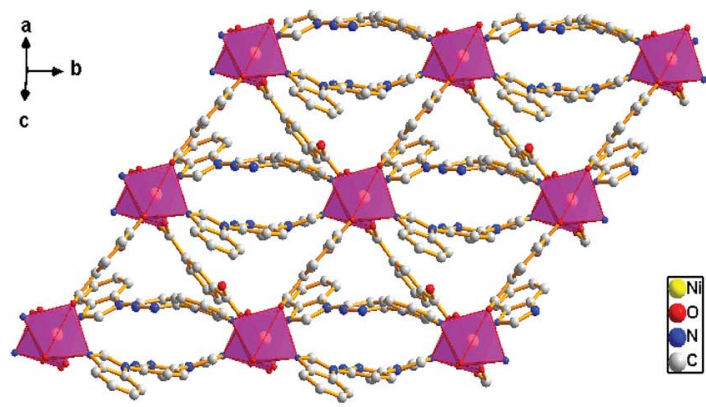

(c)

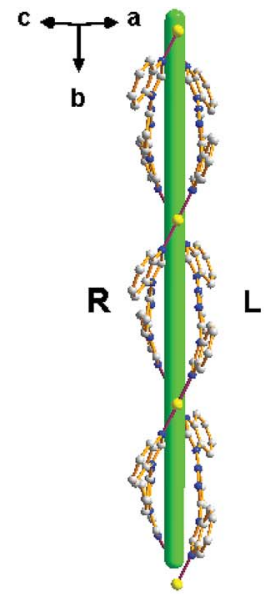

(b)

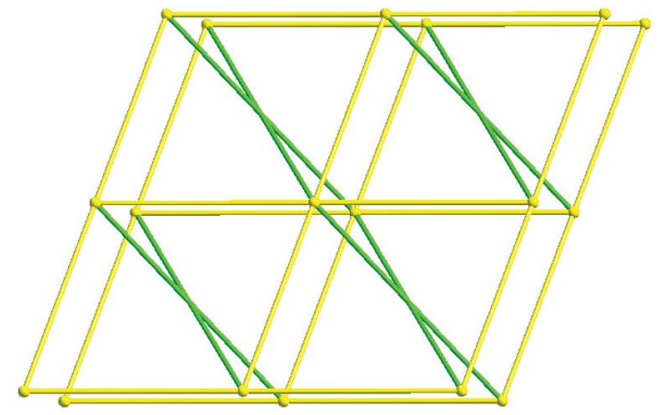

(d)

Fig. 2 View of (a) the coordination environment of Ni(॥) atom in complex 2; (b) the 1D chain of 2; (c) the 2D plane of 2; (d) the 6-connected net topology with the Schläfli symbol of $\left(4^{12} \cdot 6^{3}\right)$.

and one water molecule of coordination. The Ni1 ion is sixcoordinated and the coordination geometry around the individual $\mathrm{Ni}$ center is a distorted octahedron in which the equatorial plane is occupied by $\mathrm{O} 1, \mathrm{O} 2, \mathrm{O} 4$ and $\mathrm{O} 5$ donor atoms, and the axial sites are occupied by $\mathrm{N} 1$ and $\mathrm{N} 6$ atoms with an N1Ni1-N6 angle of $174.33^{\circ}$. The $\mathrm{O} 1, \mathrm{O} 2, \mathrm{O} 4$ and $\mathrm{O} 5$ donor atoms come from two different $1,4-\mathrm{BDC}^{2-}$ ligands and one water molecule of coordination, and N1 and N6 sites originate from the bis-bidentate bridging ligand (Fig. 3a). The lengths of $\mathrm{Ni}-\mathrm{N}$ bond are 2.062(3) and 2.084(3) $\AA$, while the lengths of $\mathrm{Ni}-\mathrm{O}$ bond is in the range of 2.026(2)-2.158(2) $\AA$.

Adjacent $\mathrm{Ni}$ centers were connected by organic ligands to form an undulating $2 \mathrm{D}$ plane structure (Fig. $3 \mathrm{~b}$ ). The 1,4- $\mathrm{H}_{2} \mathrm{BDC}$ ligand adopts a $\left(\kappa^{2}\right)-\left(\kappa^{1}\right)-\mu_{2}$ coordination mode (Scheme $2 \mathrm{C}$ ) and the $\mathbf{L}$ ligand adopt bidentate bridging coordination. The 2D layers are further extended by residual $\mathbf{L}$ ligands to give the $3 \mathrm{D}$ $\mathrm{Ni}$-organic framework (Fig. S1a $\dagger$ ), the Ni center is connected by organic ligands to four neighboring centers. Thus, Ni centers can be considered as a 4-connected node with all crystallographically independent $\mathbf{L}$ ligands and $1,4-\mathrm{BDC}^{2-}$ anion as linkers. Topological analysis reveals that 3 is a $3 \mathrm{D}$ framework of uninodal 4-connected with the point symbol of $\left\{6^{6}\right\}$ topology (Fig. 3c).

Structure of $\left[\mathrm{Mn}(\mathrm{L})(2,5-\mathrm{TDC})\left(\mathrm{H}_{2} \mathrm{O}\right)\right]_{n}$ (4). Compared with complex 1, the complex 4 was obtained when $\mathrm{Mn}$ ion was introduced in place of the $\mathrm{Ni}$ ion. Single-crystal X-ray diffraction analysis reveals that complex 4 is based on a dense 3D diamondoid framework and crystallizes in the monoclinic space group $C c$. The construction unit of the 3D framework consists of one $\mathrm{Mn}$ (II) ion, one $\mathbf{L}$ ligand, one 2,5$\mathrm{TDC}^{2-}$ anion and one water molecule of coordination. The individual $\mathrm{Mn} 1$ ion is six-coordinated, and coordination geometry around the individual Mn(II) centers is a distorted octahedron in which the equatorial plane is occupied by $\mathrm{O} 1$, $\mathrm{O} 2, \mathrm{O} 3$ and $\mathrm{O} 5$ donor atoms, and the axial sites are occupied by N1 and N6 atoms with an N1-Ni1-N6 angle of $174.42^{\circ}$. The $\mathrm{O} 1, \mathrm{O} 2, \mathrm{O} 3$ and $\mathrm{O} 5$ donor atoms come from two different 2,5$\mathrm{TDC}^{2-}$ ligands and one water molecule of coordination, and $\mathrm{N} 1$ and N6 sites originate from the bis-bidentate bridging ligand (Fig. 4a). The lengths of $\mathrm{Mn}-\mathrm{N}$ bond are 2.264(4) and 2.274(4) $\AA$, while the lengths of $\mathrm{Mn}-\mathrm{O}$ bond is in the range of $2.087(3)-2.290(3) \AA$. 


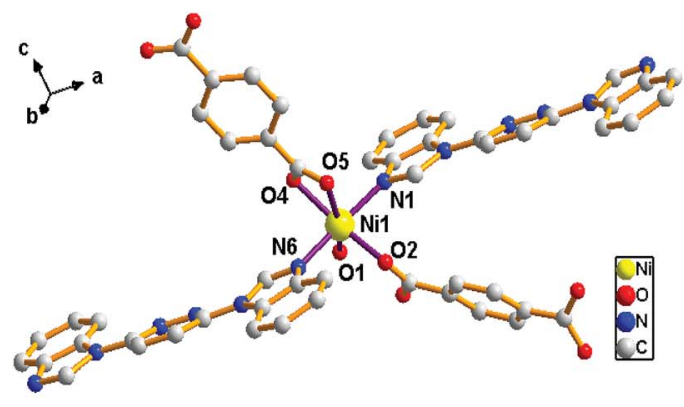

(a)

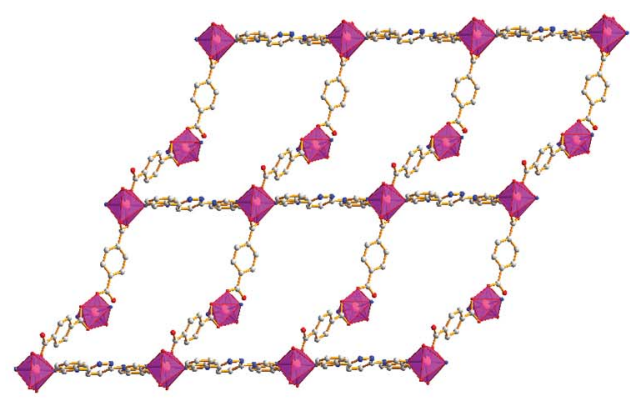

(b)

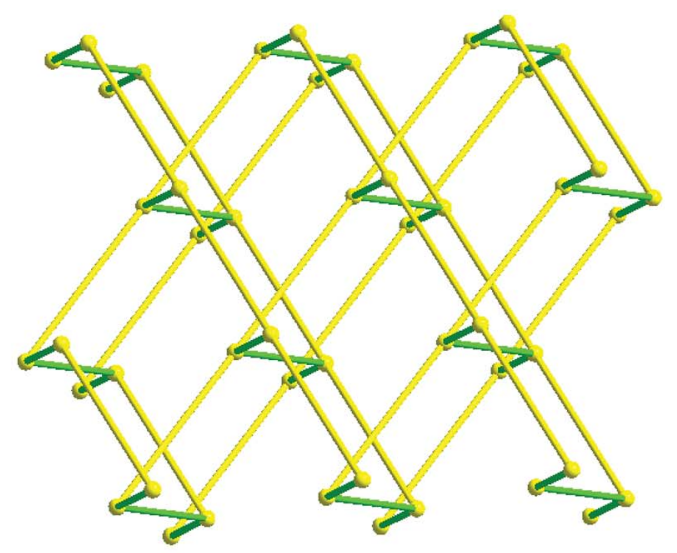

(c)

Fig. 3 View of (a) the coordination environment of $\mathrm{Ni}($ II) atom in complex 3; (b) the 2D plane of 2; (c) the 4-connected net topology with the Schläfli symbol of $\left(6^{6}\right)$.

Adjacent Mn(II) centers were connected by organic ligands to form a 2D plane network structure (Fig. $4 \mathrm{~b}$ ). The 2,5-TDC ${ }^{2-}$ ligands adopts a $\left(\kappa^{2}\right)-\left(\kappa^{1}\right)-\mu_{2}$ coordination mode (Scheme $2 \mathrm{~A}$ ) and the $\mathbf{L}$ ligand adopts bidentate bridging coordination. The 2D layers are further extended by residual carboxylate groups and $\mathbf{L}$ ligands to give 3D Mn-organic framework contained 1D channels (Fig. S1b $\dagger$ ). The structure of complex $\mathbf{4}$ is quite different from complex 1. It is worth noting that the diamondoid framework is observed in complex $\mathbf{4}$, the $\mathrm{Mn}$ centers are connected by organic ligands to four neighboring centers. Therefore, the Mn center can be considered as a 4-connected node and ligands as linkers. Topological analysis reveals that complex 4 is a 3D diamondoid framework of uninodal 4-connected with the point symbol of $\left\{6^{6}\right\}$-dia topology (Fig. 4c).

Structure of $\left[\mathrm{Mn}(\mathrm{L})(2,6-\mathrm{PYDC})\left(\mathrm{H}_{2} \mathrm{O}\right)\right]_{n}$ (5). Comparison with complex $\mathbf{4}$, the complex 5 was collected when $2,6-\mathrm{H}_{2}$ PYDC was introduced in place of $2,5-\mathrm{H}_{2}$ TDC. Complex 5 is based on an infinitely extended 1D chain framework and crystallizes in the triclinic space group $P-1$. The construction unit consists of one $\mathrm{Mn}$ ion, one $\mathbf{L}$ ligand, one 2,6-PYDC ${ }^{2-}$ anion and one water molecule of coordination. The individual Mn1 ion is sevencoordinated, and coordination geometry around the $\mathrm{Mn}$ centers is a distorted pentagonal bipyramid in which the equatorial plane is occupied by $\mathrm{O} 1, \mathrm{O}^{\# 1}, \mathrm{O} 1 \mathrm{~s}, \mathrm{O} 4$, and $\mathrm{N} 7$ donor atoms, and the axial sites are occupied by $\mathrm{N} 1$ and $\mathrm{N} 6$ atoms with an N1-Mn-N6 angle of $169.57^{\circ}$. The $\mathrm{O} 1, \mathrm{O}^{\# 1}, \mathrm{O} 1 \mathrm{~s}, \mathrm{O} 4$, and $\mathrm{N} 7$ donor atoms come from two different 2,6-PYDC ${ }^{2-}$ ligands and one water molecule of coordination, and $\mathrm{N} 1$ and $\mathrm{N} 6$ donor atoms from the bis-bidentate bridging ligand (Fig. 5a). The lengths of Mn-N bond are 2.2466(18), 2.2856(16) and 2.3306(17) $\AA$, while the lengths of $\mathrm{Mn}-\mathrm{O}$ bond is in the range of 2.1503(15)2.3921(15) ̊.

Adjacent $\mathrm{Mn}$ (II) centers were connected by carboxylate ligands to form a binuclear $\left[\mathrm{Mn}_{2}\left(\mathrm{CO}_{2}\right)_{2} \mathrm{~N}_{2}\right]$ building unit with $\mathrm{Mn} \cdots \mathrm{Mn}$ distance of $3.851 \AA$. It is worth noting that the availability of an inversion center in the binuclear metal node (Fig. 5a). Then these binuclear building units are connected via $\mathbf{L}$ ligands to generate an infinitely extended $1 \mathrm{D}$ chain (Fig. $5 \mathrm{~b}$ ). In complex 5 , the carboxylate groups in 2,6-PYDC ${ }^{2-}$ adopt a $\left(\kappa^{1}\right)$ $\left(\kappa^{1}\right)-\mu_{1}$ coordination mode (Scheme $2 \mathrm{D}$ ) and the $\mathbf{L}$ ligand adopt bidentate bridging coordination.

Structure of $[\mathrm{Mn}(\mathrm{L})(\mathbf{1}, 4-\mathrm{NDC})]_{n}$ (6). Comparison with complex 5, the complex 6 was collected when 1,4- $\mathrm{H}_{2} \mathrm{NDC}$ was introduced in place of 2,6- $\mathrm{H}_{2}$ PYDC. Single-crystal X-ray diffraction analysis reveals that complex 6 is based on a dense threedimensional framework and crystallizes in the monoclinic space group $P 2_{1} / n$. The construction unit of the 3D framework consists of one $\mathrm{Mn}$ (II) ion, one $\mathbf{L}$ ligand, and one $1,4-\mathrm{TDC}^{2-}$ 


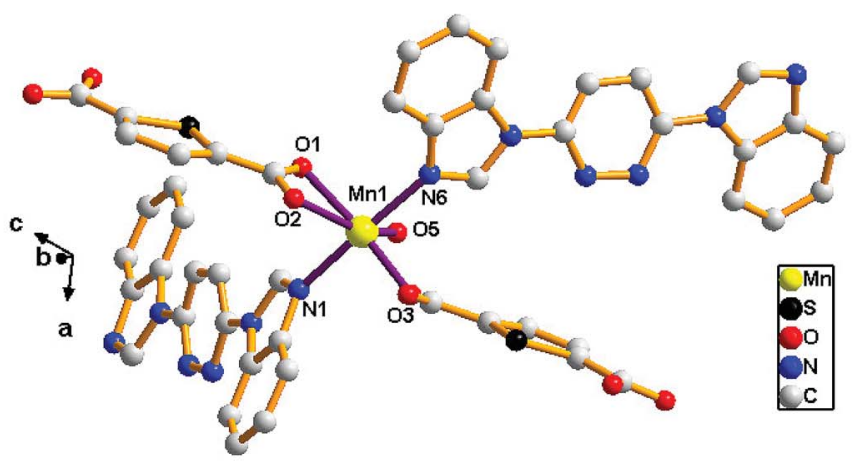

(a)

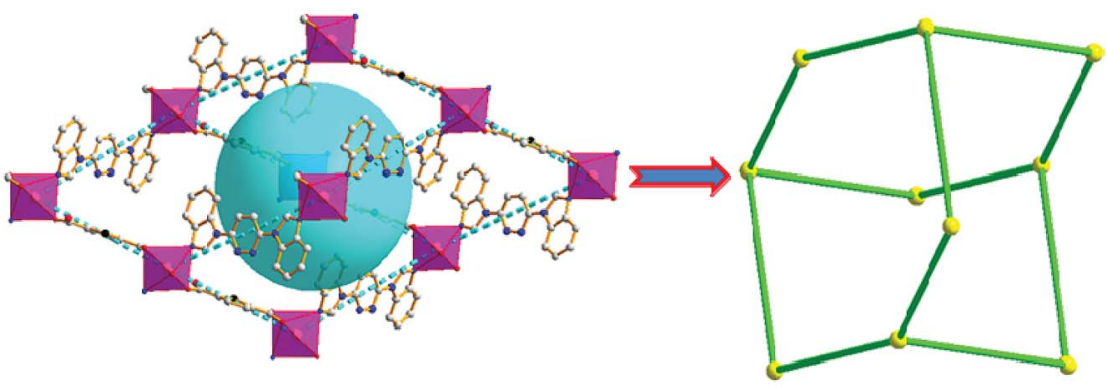

(b)

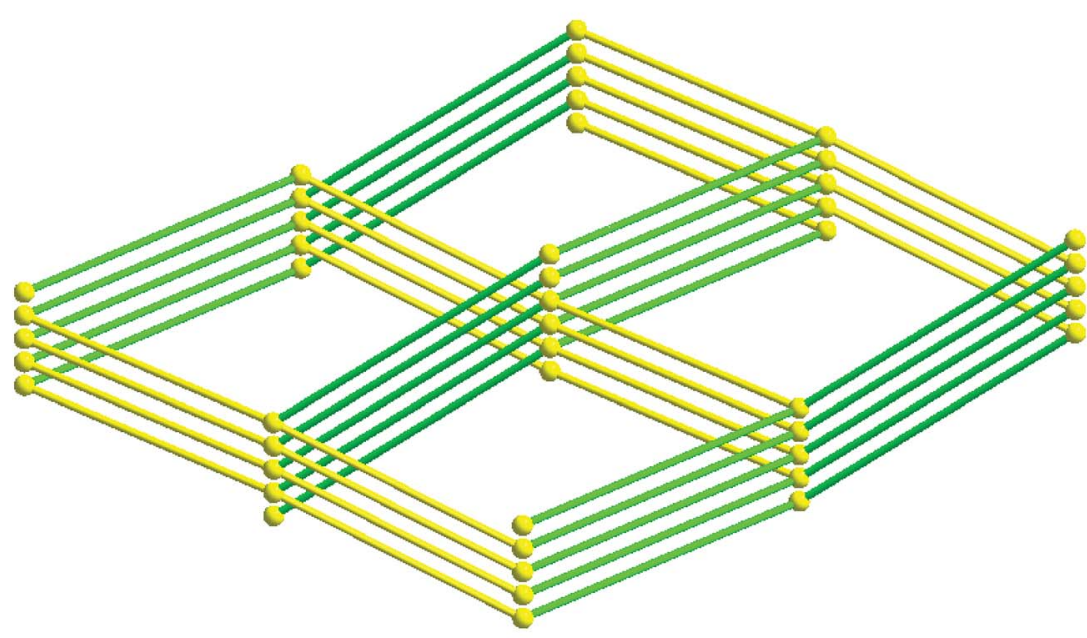

(c)

Fig. 4 View of (a) the coordination environment of $\mathrm{Mn}($ (I) atom in complex 4; (b) the 2D adamantane structure of 4; (c) the 4-connected net topology with the Schläfli symbol of $\left(6^{6}\right)$.

anion. The individual Mn1 ion is five-coordinated, and coordination geometry around the individual Mn(II) centers is a distorted trigonal bipyramid in which the equatorial plane is occupied by $\mathrm{O} 1, \mathrm{O} 2$, and $\mathrm{O} 4$ donor atoms, and the axial sites are occupied by $\mathrm{N} 1$ and $\mathrm{N} 2$ atoms with an N1-Mn1-N2 angle of $167.99^{\circ}$. The $\mathrm{O} 1, \mathrm{O} 2$, and $\mathrm{O} 4$ donor atoms come from three different 1,4-NDC ${ }^{2-}$ ligands, and N1 and N2 sites originate from the bis-bidentate bridging ligand (Fig. 6a). The lengths of $\mathrm{Mn}-\mathrm{N}$ bond are 2.242(2) and 2.263(2) ^, while the lengths of Mn-O bond is in the range of 2.138(19)-2.152(2) A.

Adjacent $\mathrm{Mn}$ (II) centers were connected by carboxylate ligands and $\mathbf{L}$ ligands to form a $2 \mathrm{D}(4,4)$ grid plane network structure (Fig. 6b), and the rectangular window of the $2 \mathrm{D}$ motif has a dimension of $c a .11 .035 \times 14.514 \AA^{2}$. The $1,4-\mathrm{NDC}^{2-}$ ligands adopts a $\left(\kappa^{1}\right)-\left(\kappa^{1}-\kappa^{1}\right)-\mu_{3}$ coordination mode (Scheme $2 \mathrm{E}$ ) and the $\mathbf{L}$ ligand adopts bidentate bridging coordination. The 


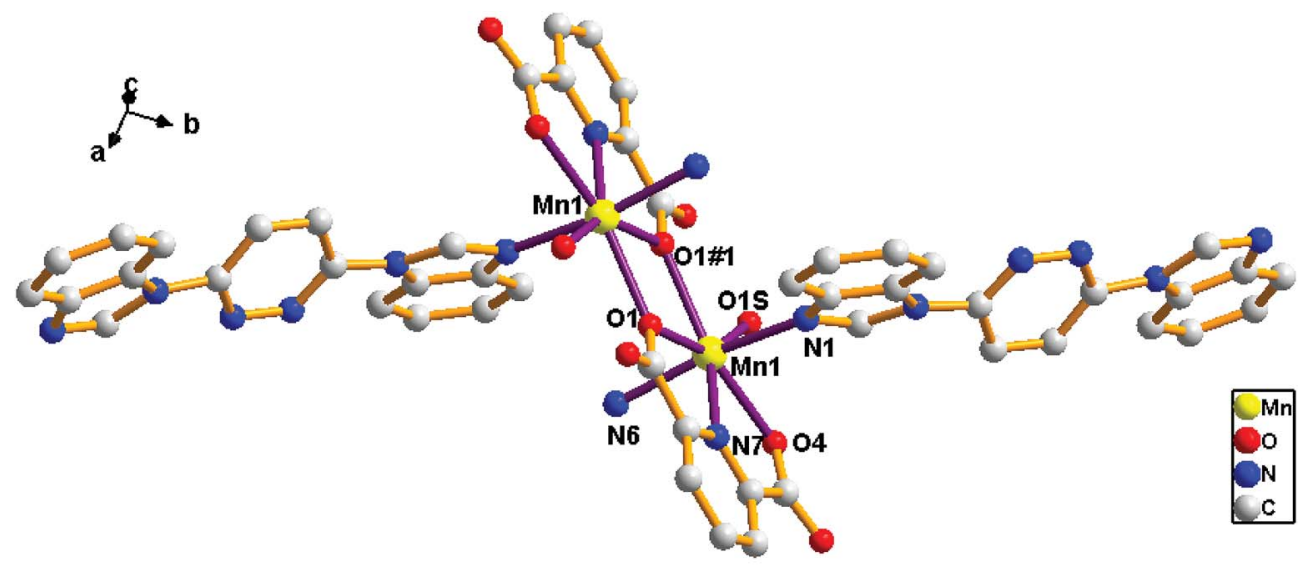

(a)

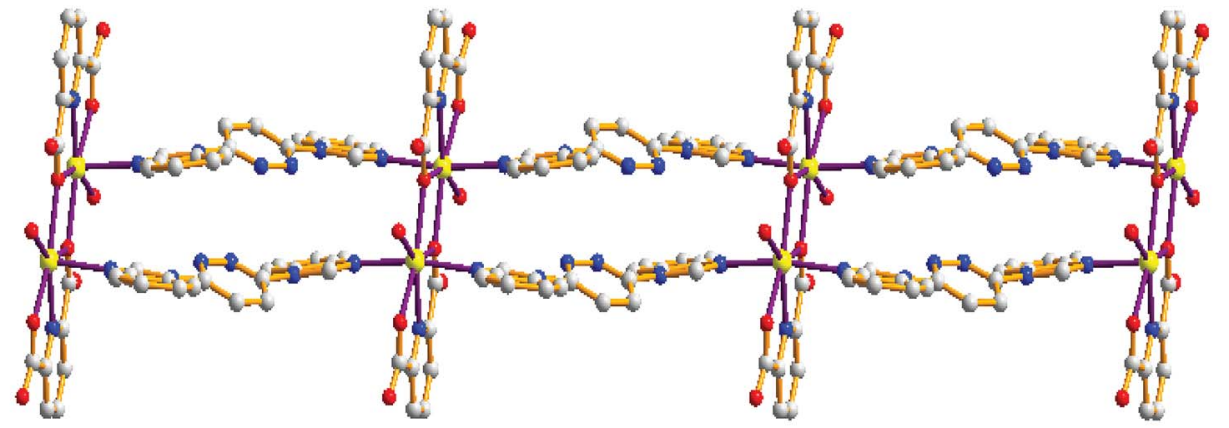

(b)

Fig. 5 View of (a) the coordination environment of $\mathrm{Mn}(॥)$ atom in complex 5; (b) the 1D chain of 5.

2D layers are further extended by residual carboxylate groups and $\mathbf{L}$ ligands to give 3D Mn-organic framework with $1 \mathrm{D}$ channels (Fig. S1c $\dagger$ ), the Mn center is connected to five neighboring centers through four $1,4-\mathrm{TDC}^{2-}$ anions and two $\mathbf{L}$ ligands. Therefore, the $\mathrm{Mn}$ (II) centers can be considered as a 6connected node and all ligands as linkers. Topological analysis reveals that it is a 3D framework of uninodal 6-connected with the point symbol of $\left\{4^{12} \cdot 6^{3}\right\}$ topology (Fig. 6c).

\section{Comparison of the structures 1-6}

Crystallographic analyses revealed that CPs 1-6 shows varied structures from the $1 \mathrm{D}$ chain (5), 2D network (2) to 3D frameworks (1, 3, 4 and 6). Complexes 1, 3 and 4 are 4-connected topological types, which 1 display a 3-fold interpenetrating 3D framework structure, the $\mathbf{3}$ is a $3 \mathrm{D}$ framework structure and $\mathbf{4}$ displays a 3D diamondoid structure. Complexes 2 and 6 are 6connected topological types, which 2 has a new 2D topological structure of helical chain structure and 6 displays a 3D framework structure. Complex 5 is a $1 \mathrm{D}$ chain structure. In addition, the carboxylate ligands exhibit varied coordination modes. The results herein further confirm that the metal center, anions, solvent system, temperature and varied coordination modes of the carboxylate ligand exert significant influence on the structural diversity of the frameworks, which can effectively regulate the structure of the CPs.

\section{Spectroscopic and thermal analysis}

PXRD analysis. The PXRD patterns of complexes 1-6 are presented in Fig. S2. $\uparrow$ The diffraction peaks of both the simulated and experimental patterns match in the key positions, indicating the phase purity of the complexes. The differences in the intensity may be contribute to the preferred orientation of the crystal samples.

TG analysis. Thermogravimetric analyses (TGA) were performed to check the thermal stability of the frameworks under nitrogen atmosphere, and the obtained plots are presented in Fig. S3. $\uparrow$ The results show that the initial mass losses of 1-6 are in accordance with the solvent losses calculated from the elemental analysis data. The TGA analysis revealed that 1-4 were stable up to $200{ }^{\circ} \mathrm{C}$. For 1, 2 and 4 its weight loss of $48.57 \%$ (1), $50.80 \%$ (2) or $44.5 \%$ (4) in the range of $200-550{ }^{\circ} \mathrm{C}(1), 200-$ $750{ }^{\circ} \mathrm{C}(2)$ or $200-650{ }^{\circ} \mathrm{C}(4)$ corresponded to the collapse of the 


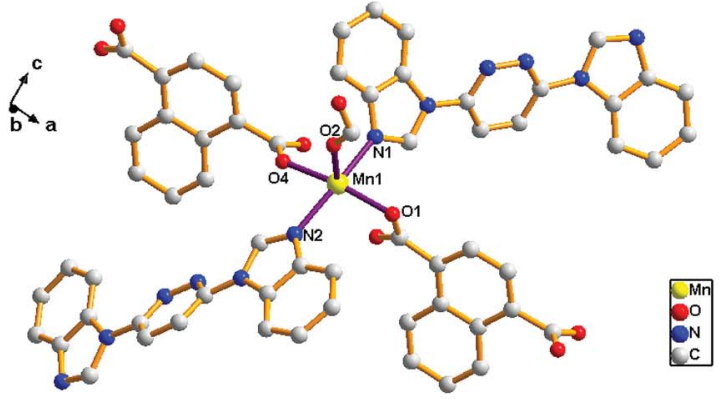

(a)

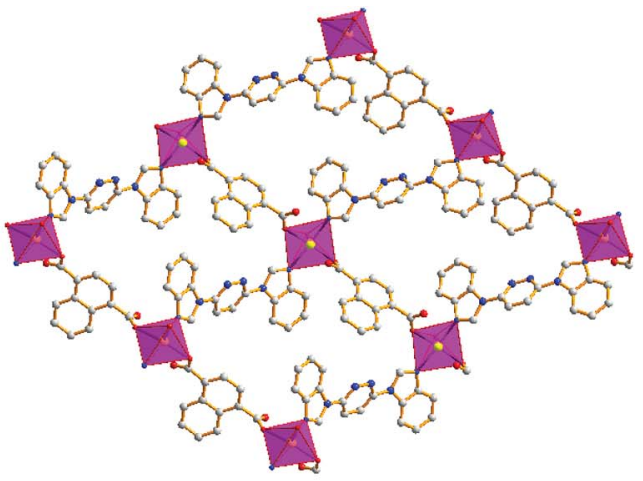

(b)

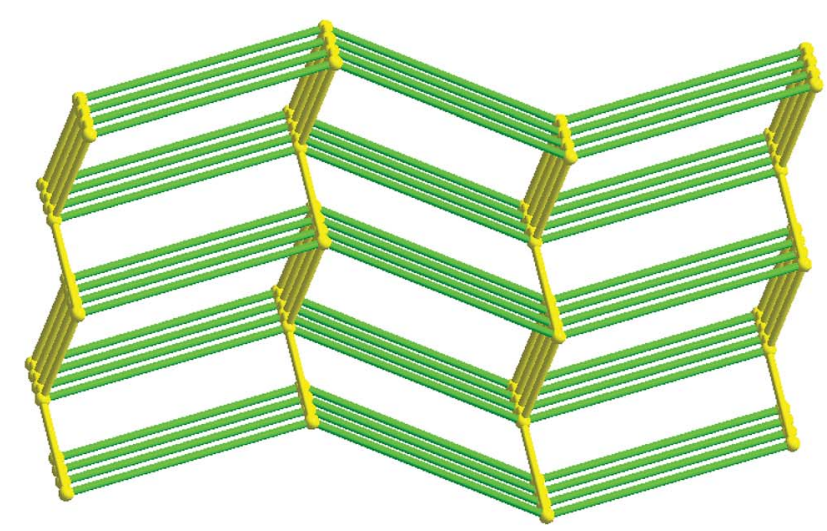

(c)

Fig. 6 View of (a) the coordination environment of $\mathrm{Mn}(॥)$ atom in complex 6; (b) the 2D plane of 6; (c) the 6-connected net topology with the Schläfli symbol of $\left(4^{12} \cdot 6^{3}\right)$.

framework. For 3, the first weight loss of $12.04 \%$ in the range of 200-300 ${ }^{\circ} \mathrm{C}$ corresponded to the loss of water molecules and partial framework decomposition and a further weight loss was observed at about $400{ }^{\circ} \mathrm{C}$, corresponding to the collapse of the framework. For 5, the first weight loss of 5.33\% in the range of 100-170 ${ }^{\circ} \mathrm{C}$ corresponded to the loss of water molecules and partial framework decomposition and a further weight loss was observed at about $280{ }^{\circ} \mathrm{C}$, corresponding to the collapse of the framework. For $\mathbf{6}$, the TGA analysis revealed that $\mathbf{6}$ were stable up to $375{ }^{\circ} \mathrm{C}$. The weight loss of $50 \%$ in the range of $375-550{ }^{\circ} \mathrm{C}$ corresponded to the loss of collapse of the framework.

Magnetic properties. Variable-temperature magnetic susceptibility of complexes 1-6 studies were carried out on a SQUID MPMS-XL-7 with an applied magnetic field of 1000 Oe and in the temperature range of 2-300 K. Magnetic data as plots of $\chi_{\mathrm{M}} T$ and $\chi_{\mathrm{m}}{ }^{-1}$ versus $T$ are depicted in Fig. 7 . The results showed that complex 2 was ferromagnetic coupling and complexes 1, 3-6 were antiferromagnetic. For 2, at room temperature, the product $\chi_{M} T$ is slightly higher than expected for one isolated $\mathrm{Ni}(\mathrm{II})$ ions with $g=1.1$ (this would correspond to 1.17 emu $\mathrm{mol}^{-1} \mathrm{~K}$ ), indicating the presence of predominantly ferromagnetic interactions in 2 . They increase upon cooling with a more pronounced slope as the temperature becomes closer to zero to reach maxima at $1.62 \mathrm{emu} \mathrm{mol}^{-1} \mathrm{~K}$, near $15 \mathrm{~K}$, and below $15 \mathrm{~K}$, it decreases quickly to $0.62 \mathrm{emu} \mathrm{mol}^{-1} \mathrm{~K}$ at $3 \mathrm{~K}$, which might be mainly due to the presence of zero-field splitting (ZFS) for Ni(II) ions. ${ }^{19}$ Fitting of the $\chi_{\mathrm{m}}{ }^{-1}-T$ above $25 \mathrm{~K}$ using the Curie-Weiss law $\chi_{\mathrm{m}}=C /(T-\theta)$ gives the curie constants $C$ $=1.17 \mathrm{emu} \mathrm{mol}{ }^{-1} \mathrm{~K}$ and the weiss constants $\theta=1.65 \mathrm{~K}$, which support the presence of overall ferromagnetic interactions in the complex 2. The carboxylate ligands that link the double helical chains to form $2 \mathrm{D}$ net will provide a pathway for weak antiferromagnetic coupling. ${ }^{20}$ For $\mathbf{1}, 3-6$, the magnetic coupling through this ligands in this bridging mode is very weak and usually antiferromagnetic. The maximum $\chi_{\mathrm{M}} T$ value of complexes 1, 3-6 at $300 \mathrm{~K}$ are closer to $1.31,1.95,4.45,4.15$, and $4.55 \mathrm{emu} \mathrm{mol}^{-1} \mathrm{~K}$, respectively, which is larger than the spinonly value for magnetically isolated systems, as expected for a $\mathrm{Mn}$ (II) system with a significant contribution from the unquenched orbital momentum in an octahedral ligand field. ${ }^{21}$ The curve indicates the typical antiferromagnetic and spinorbit coupling interactions present in the complexes 1, 3-6. With lowering of temperature, the $\chi_{M} T$ values are smoothly decreases when the temperature closer to $2 \mathrm{~K}$ and obtain a minimum $\chi_{\mathrm{M}} T$ values (Table 1 ), indicating that antiferromagnetic interactions occurred. The magnetic susceptibility $\chi_{\mathrm{m}}{ }^{-1}$ versus $T$ obeys the Curie-Weiss law $\left[\chi_{\mathrm{m}}=C(T-\theta)\right]$ gives a $C$ and $\theta$ value at the corresponding temperature range (Table 

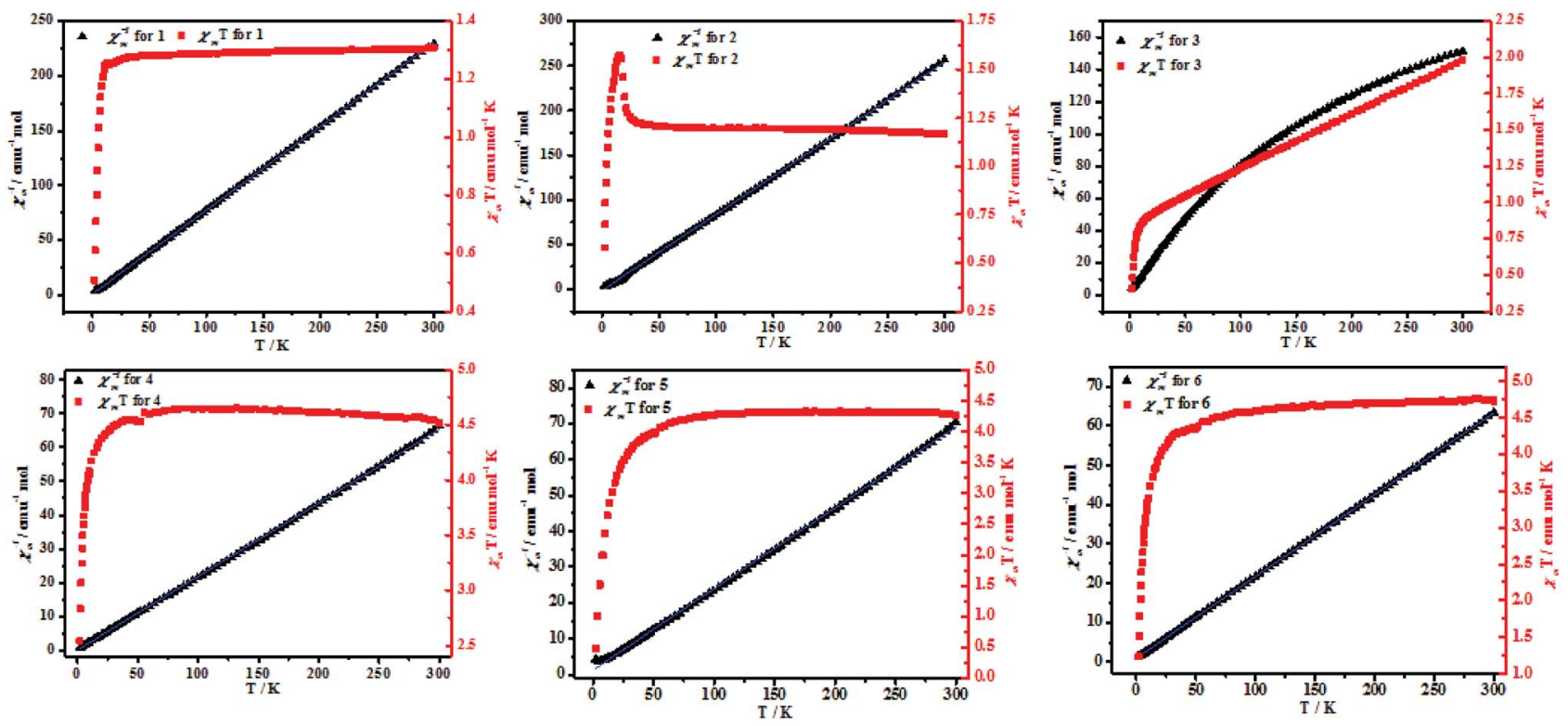

Fig. 7 Temperature-dependent magnetic susceptibilities of 4-6 in the temperature range of 2-300 K under an applied magnetic field of 1000 O.

Table 2 Magnetic properties date of complexes 1-6

\begin{tabular}{|c|c|c|c|c|c|c|}
\hline & 1 & 2 & 3 & 4 & 5 & 6 \\
\hline$T(\mathrm{~K})$ & $25-300$ & $25-300$ & $25-300$ & $60-300$ & $50-300$ & $70-300$ \\
\hline$C\left(\mathrm{emu} \mathrm{mol}{ }^{-1} \mathrm{~K}\right)$ & 1.3 & 1.17 & 1.94 & 4.59 & 4.42 & 4.81 \\
\hline$\chi_{\mathrm{M}} T$ value at $300 \mathrm{~K}$ & 1.31 & 1.17 & 1.95 & 4.45 & 4.15 & 4.55 \\
\hline$\chi_{\mathrm{M}} T$ value at $2 \mathrm{~K}$ & 0.51 & 0.62 & 0.41 & 2.52 & 0.31 & 1.56 \\
\hline
\end{tabular}

1), respectively. The negative $\theta$ further confirms antiferromagnetic interactions present in the complexes 1, 3-6. It is worth noting that the spin-orbit coupling is contributing for the negative weiss constant (Table 2). ${ }^{22}$

\section{Conclusion}

In conclusion, six new CPs with a 3,6-bis(benzimidazol-1-yl) pyridazine ligand and different dicarboxylate ligands as the auxiliary ligands have been structurally, magnetically and catalytically characterized in this work. Results analysis manifests that complexes 1-6 have high thermal stability. Complex 2 has a new topological structure and complex $\mathbf{4}$ has a diamond structure. The polycarboxylates plays an important role in the assembly of the final complexes structures. Moreover, complex 2 was ferromagnetic coupling and complexes 1, 3-6 were antiferromagnetic.

\section{Conflicts of interest}

There are no conflicts to declare.

\section{Acknowledgements}

This work was financially supported by the National Natural Science Foundation of China (No. 21361026).

\section{References}

1 (a) C.-W. Kung, K. Otake, C.-T. Buru, S. Goswami, Y.-X. Cui, J.-T. Hupp, A.-M. Spokoyny and O.-K. Farha, J. Am. Chem. Soc., 2018, 140, 3871-3875; (b) P. Thuéry and J. Harrowfield, Inorg. Chem., 2017, 56, 13464-13481; (c) J.-T. Dovgan, M.-J. Polinski, B.-Q. Mercado and E.-M. Villa, Cryst. Growth Des., 2018, 18, 5332-5341; (d) S.-K. Seth, CrystEngComm, 2013, 15, 1772-1781; (e) A. Hossain, S.-K. Seth, A. Bauzá, S. Mukhopadhyay and A. Frontera, Polymers, 2018, 10, 182-196.

2 (a) Z.-Z. Xue, D. Zhang, J. Pan, S.-D. Han, J.-H. Li and G.-M. Wang, Dalton Trans., 2017, 46, 13952-13956; (b) N. Tannert, S.-J. Ernst, C. Jansen, H.-J. Bart, S.-K. Henningerc and C. Janiak, J. Mater. Chem. A, 2018, 6, 17706-17712.

3 (a) F. Haque, A. Halder and D. Ghoshal, Cryst. Growth Des., 2018, 18, 5231-5244; (b) D. Mondal, M.-C. Majee, S. Kundu, 
M. Mörtel, G. Abbas, A. Endo, M.-M. Khusniyarov and M. Chaudhury, Inorg. Chem., 2018, 57, 1004-1016.

4 (a) Y.-H. Tang, F. Wang and J. Zhang, Dalton Trans., 2018, 47, 4032-4035; (b) C. Huang, Y.-Y. Zhang, H.-Y. Yang, D.-D. Wang, L.-W. Mi, Z.-C. Shao, M.-J. Liu and H.-W. Hou, Cryst. Growth Des., 2018, 18, 5674-5681; (c) S.-M. Tang, J. Zhou, H.-H. Zou, X. Liu and L. Zhang, Inorg. Chem., 2018, 57, 1242; (d) D. Zhao, X.-H. Liu, J.-H. Guo, H.-J. Xu, Y. Zhao, Y. Lu and W.-Y. Sun, Inorg. Chem., 2018, 57, 26952704; (e) Y.-S. Kang, Y. Lu, K. Chen, Y. Zhao, P. Wang and W.-Y. Sun, Coord. Chem. Rev., 2019, 378, 262-280.

5 (a) P.-P. Cen, S. Zhang, X.-Y. Liu, W.-M. Song, Y.-Q. Zhang, G. Xie and S.-P. Chen, Inorg. Chem., 2017, 56, 3644-3656; (b) Y.-S. Ding, N.-F. Chilton, R. E.-P. Winpenny and Y.-Z. Zheng, Angew. Chem., Int. Ed., 2016, 55, 16071-16074; (c) F. El-Khatib, B. Cahier, F. Shao, M. Lopez-Jorda, R. Guillot, E. Riviere, H. Hafez, Z. Saad, J.-J. Girerd, N. Guihery and T. Mallah, Inorg. Chem., 2017, 56, 4601-4608.

6 (a) M. Chen, H. Zhao, E.-C. Sanudo, C.-S. Liu and M. Du, Inorg. Chem., 2016, 55, 3715-3717; (b) Y.-Z. Zhang, H.-H. Zhao, E. Funck and K.-R. Dunbar, Angew. Chem., Int. Ed., 2015, 54, 5583-5587.

7 (a) S. Goswami, G. Leitus, B.-K. Tripuramallu and I. Goldberg, Cryst. Growth Des., 2017, 17, 4393-4404; (b) S. Ganguly, S. Mukherjee and P. Dastidar, Cryst. Growth Des., 2016, 16, 5247-5259; (c) T.-P. Hu, B. Zheng, X. Wang and X. Hao, CrystEngComm, 2015, 17, 9348-9356.

8 X.-X. Wang, X.-Q. Wang, X.-Y. Niu and T.-P. Hu, CrystEngComm, 2016, 18, 7471-7477.

9 H.-B. Zhou, K. Wu, C. Chen, R.-Y. Dong, Y.-S. Liu and X.-P. Shen, Eur. J. Inorg. Chem., 2017, 3946-3952.

10 S. Sujit, H. Susanta, K. Parimal, D. Supriya, R. Gopalan, S.-E. Carolina and M. Sasankasekhar, Inorg. Chem., 2011, 50, 7257-7267.

11 (a) J.-L. Dong, K.-H. He, D.-Z. Wang, Y.-H. Zhang and D.-H. Wang, J. Solid State Chem., 2018, 263, 164-171; (b)
Z.-Y. Li, J.-W. Dai, M. Damjanovic, T. Shiga, J.-H. Wang, J. Zhao, H. Oshio, M. Yamashita and X.-H. Bu, Angew. Chem., Int. Ed., 2019, 58, 4339-4344.

12 (a) B. Xia, Y. Zhou, Q.-L. Wang, X.-F. Xu, Y.-Z. Tong, X.-H. Bu and J.-R. Li, Dalton Trans., 2018, 47, 15888-15896; (b) S.-D. Han, X.-H. Miao, S.-J. Liu and X.-H. Bu, Dalton Trans., 2015, 44, 560-567.

13 (a) B. Aguila, Q. Sun, X.-L. Wang, E. O'Rourke, A.-M. Al-Enizi, A. Nafady and S.-Q. Ma, Angew. Chem., Int. Ed., 2018, 57, 10107-10111; (b) X.-L. Yang, M.-H. Xie, C. Zou, Y.-B. He, B.-L. Chen, M. O'Keeffe and C.-D. Wu, J. Am. Chem. Soc., 2012, 134, 10638-10645.

14 (a) S.-B. Zhou, X.-F. Wang, C.-C. Du, D.-Z. Wang and D.-Z. Jia, CrystEngComm, 2017, 19, 3124-3137; (b) K. Fan, S.-S. Bao, W.-X. Nie, C.-H. Liao and L.-M. Zheng, Inorg. Chem., 2018, 57, 1079-1089.

15 X.-F. Wang, C.-C. Du, S.-B. Zhou and D.-Z. Wang, J. Mol. Struct., 2017, 1128, 103-110.

16 J.-P. Li, J.-Z. Fan and D.-Z. Wang, J. Solid State Chem., 2016, 239, 251-258.

17 V.-A. Blatov, and D.-M. Proserpio, TOPOS4.0, program package for multipurpose crystallochemical analysis, University of Milano, Italy, 2009.

18 G.-M. Sheldrick, SHELXS-2014, Program for the Crystal Structure Solution, University of Göttingen, Germany, 2014.

19 A.-R. Paital, W.-T. Wong, G. Aromí and D. Ray, Inorg. Chem., 2007, 46, 5727-5733.

20 B.-W. Hu, J.-P. Zhao, J. Tao, X.-J. Sun, Q. Yang, X.-F. Zhang and X.-H. Bu, Cryst. Growth Des., 2010, 10, 2829-2831.

21 (a) C.-C. Du, X. F. Wang, S.-B. Zhou, D.-Z. Wang and D.-Z. Jia, CrystEngComm, 2017, 19, 6758-6777; (b) J. Zhao, W.-W. Dong, Y.-P. Wu, Y.-N. Wang, C. Wang, D.-S. Li and Q.-C. Zhang, J. Mater. Chem. A, 2015, 3, 6962-6969.

22 D.-Z. Wang, J.-Z. Fan, D.-Z. Jia and C.-C. Du, CrystEngComm, 2016, 18, 6708-6723. 